\title{
Inequality and Electoral Accountability: Class-Biased Economic Voting in Comparative Perspective
}

Timothy Hicks, University College London

Alan M. Jacobs, University of British Columbia

J. Scott Matthews, Memorial University of Newfoundland

Do electorates hold governments accountable for the distribution of economic welfare? Building on the finding of "class-biased economic voting" in the United States, we examine how electorates in advanced democracies respond to alternative distributions of income gains and losses. Drawing on individual-level electoral data and aggregate election results across 15 countries, we examine whether lower- and middle-income voters defend their distributive interests by punishing governments for concentrating income gains among the rich. We find no indication that non-rich voters punish rising inequality and substantial evidence that electorates positively reward the concentration of aggregate income growth at the top. Our results suggest that governments commonly face political incentives systematically skewed in favor of inegalitarian economic outcomes. At the same time, we find that the electorate's tolerance of rising inequality has its limits: class biases in economic voting diminish as the income shares of the rich grow in magnitude.

$\mathrm{D}$ o democratic processes contribute to more equal economic outcomes? While individuals of differing means may have unequal power in the marketplace, they notionally have equal votes in the democratic political sphere. If citizens are aware of and willing to defend their material interests in the voting booth, there should be electoral profit for governments that distribute economic gains widely, maximizing welfare enhancements for the many. Likewise, governments that preside over a mounting concentration of income among the few at the top should see punishment at the polls. From this perspective, the rise in inequality in many advanced democracies over the past three decades - in particular, the increasing share of national income received by the very rich (Piketty and Saez 2013; OECD 2008)—represents an important puzzle. Why have mechanisms of electoral accountability not induced office-seeking incumbents to achieve or preserve more egalitarian economic outcomes?
In this article, we pursue this question through the analysis of patterns of electoral responsiveness to the distribution of economic gains and losses. The voluminous literature on economic voting establishes that the economy matters - that changes in economic conditions regularly influence voters' evaluations of government performance and, in turn, how they cast their ballots on election day. ${ }^{1}$ Largely absent from this literature, however, is a consideration of how material distribution matters for the vote. ${ }^{2}$ What kind of distribution of economic gains and losses does the electorate reward or punish? Do voters reward distributive outcomes that favor their own economic interests?

In recent work, Bartels (2008) provides a striking answer when it comes to the US electorate. He finds that, perversely, American voters respond strongly and positively to growth at the very top of the income distribution, controlling for mean income growth. Indeed, even lower-income Americans

Timothy Hicks (t.hicks@ucl.ac.uk) is a lecturer in public policy at University College London, WC1H 9QU, UK. Alan M. Jacobs (alan.jacobs@ubc.ca) is an associate professor of political science at the University of British Columbia, Vancouver, BC, V6T 1Z1, Canada. J. Scott Matthews (scott.matthews@mun.ca) is an associate professor of political science at the Memorial University of Newfoundland, St. Johns, NL, A1B 3X9, Canada.

Financial support for this research was provided by the University of British Columbia Humanities and Social Sciences Research Grant Program and the Canadian Opinion Research Archive at Queen's University (Kingston, Ontario). Data and supporting materials necessary to reproduce the numerical results in the article are available in the JOP Dataverse (https://dataverse.harvard.edu/dataverse/jop). An online appendix with supplementary material is available at http://dx.doi.org/10.1086/686157.

1. Useful recent summaries of the economic voting literature can be found in Anderson (2007) and Duch and Stevenson (2008).

2. For exceptions, see Ansolabehere, Meredith, and Snowberg (2014), Hopkins (2012), and Mutz and Mondak (1997).

The Journal of Politics, volume 78, number 4. Published online August 2, 2016. http://dx.doi.org/10.1086/686157

(C) 2016 by the Southern Political Science Association. All rights reserved. 0022-3816/2016/7804-0009\$10.00 
reward incumbents for generating income gains among the very rich. Such "class-biased economic voting" (CBEV), as Bartels terms it, may have profound consequences for the political economy of inequality, systematically incentivizing governments to magnify the concentration of resources among the most affluent, while punishing incumbents who preside over more broadly shared economic gains.

Meanwhile, however, we know little about how voters in other advanced democracies respond to alternative distributions of economic gains. It is readily conceivable that the effects Bartels identifies are confined to voters in the United States, forming part of a larger matrix of features of the American political system that amplify the influence of the economically advantaged (e.g., Gilens 2012; Hacker and Pierson 2011). Conversely, the forces that plausibly generate CBEV in the United States - features of electoral politics that privilege holders of economic resources - might be expected to operate quite generically across capitalist democracies.

In this article, we ask how voters across a wide sample of advanced democracies respond to distributive outcomes that channel income gains to the rich at the expense of the rest. The empirical analysis proceeds in two parts. First, following Bartels, we merge income growth data with long time series of individual-level election-study data in four countries: Canada, Sweden, the United Kingdom, and-updating Bartels's analysis - the United States. Second, to expand our sample, we analyze the relationship between the distribution of income growth and aggregate election results for a much larger group of advanced democracies. We further leverage this larger sample to examine how the pattern of CBEV across space and time is conditioned by inequality itself: Do class biases in voting patterns strengthen or weaken as the distribution of income itself becomes more skewed?

Our results indicate that voters, by and large, do a poor job at defending their own distributional interests: forms of class-biased economic voting are endemic to advanced democracies across diverse political-economic contexts. We observe virtually no indication that electorates punish rising inequality in favor of the rich or reward distributions of income that favor the non-rich. And we find considerable evidence that lower- and middle-income voters positively reward governments for redistributing income toward the most affluent. At the same time, we find that the strength of this effect is inversely related to the level of inequality itself: the political reward for inegalitarian outcomes shrinks as the income share of the rich grows.

The article's findings have important implications for our understanding of both economic voting and the political economy of inequality. In exposing the distributional dimension of economic voting to empirical scrutiny, the article uncovers broad-based evidence of a distinctive form of voter "irrationality": the tendency of much of the electorate, much of the time, to vote against its own distributive interests. The results also have important, if normatively mixed, implications for our understanding of the comparative politics of inequality. On the one hand, the analyses yield evidence of a specific and unexpected effect of income differentials on political outcomes in advanced democracies. Electoral processes in the countries we analyze frequently fail to incentivize politicians to broadly disperse the fruits of economic growth - and, often, they appear to do quite the opposite. More generally, the findings illuminate a specific link between affluence and political influence-so well documented in the US context - that operates well beyond the US political system. At the same time, the empirical pattern reported here suggests that the electorate's tolerance for rising inequality has its limits: class-biased economic voting wanes as income becomes increasingly concentrated at the top.

\section{CLASS-BIASED ECONOMIC VOTING: AMERICAN EXCEPTIONALISM?}

A large body of cross-national evidence points to the importance of retrospective evaluations of the economy in shaping vote choices (Anderson 2000; Duch and Stevenson 2008; Fiorina 1981; Kinder and Kiewiet 1981; Kramer 1971; Lewis-Beck 1988). As economic conditions deteriorate, voters are less likely to return incumbents to office; conversely, when conditions are improving, voters are more likely to support incumbents. Aside from its importance to election forecasters (Lewis-Beck and Stegmaier 2013), this regularity is widely interpreted as a triumph for democratic accountability. That said, recent work has documented significant, systematic departures from a normatively ideal model of retrospective economic evaluation. Voters tend, for instance, to respond largely to economic conditions in the election year, mostly ignoring the rest of the incumbent's term (Achen and Bartels 2004; Healy and Lenz 2014; Huber, Hill, and Lens 2012), and citizens' perceptions of the national economy have been shown to be subject to considerable political bias, with supporters of the incumbent party evaluating the economy more favorably than out-party supporters (Evans and Andersen 2006; Evans and Pickup 2010; Wlezien, Franklin, and Twiggs 1997).

\section{Bartels's findings on the United States}

Bartels (2008, chap. 4) uncovers in the US electorate what appears to be an especially troubling departure from the normative ideal. When considering whose economic fortunes shape retrospective voting, scholars have typically 
homed in on two possibilities. "Sociotropic" models generally focus on the effect of national economic conditions, while "egocentric" models posit an effect of personal economic outcomes on vote choice (Key 1968; Kinder and Kiewiet 1981; Kramer 1971). Each of these possibilities has normative appeal as a mechanism for ensuring democratic accountability and incentivizing welfare-maximizing governmental performance. In the first instance, voters are responding to outcomes for the collectivity of which they form a part (sociotropic voting); in the second instance, each voter wields his or her vote in defense of his or her own economic interests (egocentric voting).

Bartels, however, finds striking evidence in American National Election Study (ANES) data that US voters do neither of these things. Bartels estimates individual-level models of economic voting in post-war US presidential elections, employing measures of election year income growth as explanatory variables. To examine how economic accountability interacts with distributional dynamics, Bartels disaggregates the analyses by income group in two respects. First, in a model of incumbent voting, income-group-specific income growth measures appear as predictors, alongside mean income growth, allowing for an estimate of whose gains and losses matter. Second, Bartels estimates this vote model separately for voters within different income terciles, allowing him to identify whose economy matters for whom.

Bartels's most important results for present purposes, as reported in his tables 4.5 and 4.6, are displayed here in table 1 . The table presents the results of individual-level probit models with voting for the incumbent as the dependent variable. All models include as explanatory variables the rate of mean income growth in the election year and the rate of election year income growth for households at the 95th percentile of income. Controls for the length of incumbent tenure and whether the voter identifies with the party of the incumbent are also included. Estimates are for all presidential elections, 1952-2004.

The first two columns of table 1 provide the coefficients and standard errors for the full sample of all respondents who reported voting in an election. The core finding is that the electorate as a whole appears to be highly responsive to income growth at the top of the income scale, after controlling for mean income growth. We also see that voters are essentially nonresponsive to mean income growth itself, after factoring out top-income growth. The second and third models restrict the sample to, respectively, the bottom and middle tercile of voters by income. In the second model, estimated for the low-income group, we see that low-income voters are highly responsive to top-income growth (controlling for mean income growth) — and much more so than to mean income growth itself. In the estimates for the third model, we observe that middle-income American voters are also strongly responsive to income growth among the richest $5 \%$ of the population, controlling for mean income growthabout twice as responsive as they are to mean growth.

\section{Conceptualizing class-biased economic voting}

Bartels refers to this electoral pattern as evidence of "classbiased economic voting," and we adopt Bartels's terminology in the analysis below. ${ }^{3}$ For comparative purposes, however, we define and unpack the concept of class-biased economic voting (CBEV) in a manner abstracted from the details of the US results. Specifically, we define CBEV by reference to the electorate's response to the distribution of income gains between the highest-income households and all other households. The critical question we examine is this: For a given amount of aggregate growth, how do all, low-income, and middle-income voters respond to differing allocations of that growth between the rich and the rest?

This electoral response can be defined more precisely by reference to a statistical model of the general form that Bartels employs. We demonstrate the following point formally in the appendix (section B.1; appendix available online), and so we focus on the intuition here. If both mean income growth $\left(\right.$ Growth $\left.{ }^{\mathrm{M}}\right)$ and income growth for the richest 5\% (Growth ${ }^{\mathrm{TS}}$ ) are included in a model of voting, the coefficient on Growth ${ }^{\mathrm{T5}}$ indicates the effect on voting patterns of enriching the rich while holding the mean growth rate constant. With mean growth held constant, any increase in income growth for one group necessarily implies lower income growth for all other groups taken as a whole. Thus, the coefficient estimate for Growth ${ }^{\mathrm{T} 5}$ in this model indicates the effect of a reallocation of income gains from the bottom $95 \%$ of earners to the top $5 \%{ }^{4}$

Voters outside the top 5\% who are prepared to advance their distributive interests at the ballot box ought to respond adversely to such an upward redistribution of net gains; that is, we should observe a negative coefficient on Growth $^{\text {T5 }}$. We term such a behavioral response inequality aversion. Where non-rich voters fail to respond to income gains among the rich (net of mean growth), we term the

3. While we employ Bartels's terminology, we emphasize that the phenomenon represents a bias with respect to income groups, rather than social "classes" per se.

4. Strictly speaking, this logic assumes a model in which Growth ${ }^{\mathrm{T5}}$ measures the mean income growth rate of the top 5\%, whereas Bartels uses a measure of income growth at the 95th percentile. In our own analyses below, we employ measures of mean growth for the top 5\% wherever available, though we also find that the two measures of top-income growth generate similar results. 
Table 1. United States: The Electoral Impact of Income-Specific Growth among All, Low-Income, and Middle-Income Voters for Presidential Elections in the Period 1952-2004 (Estimates as Presented in Bartels 2008, Tables 4.5 and 4.6)

\begin{tabular}{|c|c|c|c|c|c|c|}
\hline & \multicolumn{2}{|c|}{ All } & \multicolumn{2}{|c|}{ Low Income } & \multicolumn{2}{|c|}{ Middle Income } \\
\hline & $b$ & SE & $b$ & SE & $b$ & SE \\
\hline Vote for incumbent & & & & & & \\
\hline Incumbent tenure & -.040 & $(.013)$ & -.048 & $(.012)$ & -.029 & $(.011)$ \\
\hline Incumbent pid & 1.607 & $(.071)$ & 1.545 & $(.066)$ & 1.580 & $(.069)$ \\
\hline Growth $^{M}$ & .023 & $(.020)$ & -.031 & $(.027)$ & .052 & $(.012)$ \\
\hline Growth $^{\mathrm{T} 5}$ & .102 & $(.010)$ & .097 & $(.014)$ & .102 & $(.010)$ \\
\hline Intercept & .100 & $(.121)$ & .311 & $(.012)$ & -.082 & $(.076)$ \\
\hline Log likelihood & $-6,424.4$ & & $-1,715.3$ & & $-2,002.0$ & \\
\hline Pseudo $R^{2}$ & .42 & & .42 & & .40 & \\
\hline$N$ & 15,976 & & 4,242 & & 4,848 & \\
\hline
\end{tabular}

observed behavioral pattern (a null effect of Growth $^{\mathrm{T} 5}$ on the votes of the non-rich) indifference to inequality. Finally, where lower- and middle-income voters actually reward gains at the top (again, holding mean growth constant), we refer to an effective demand for inequality. ${ }^{5}$

While a demand for inequality represents the strongest form of CBEV - incentivizing incumbents to concentrate welfare gains among the most affluent-electoral indifference to inequality is also likely to have important implications for the class bias of democratic politics. First, to the extent that market - for example, financialization (Lin and TomaskovicDevey 2013), global competition for "superstars" (Saez and Veall 2005), or skill-biased technological change (Kaplan and Rauh 2013)_-generate rising income shares for top earners, the absence of affirmative policy action to redistribute income will tend to yield rising inequality. As Hacker (2004) and Hacker and Pierson (2011) have emphasized, policy stability (or "drift") in a changing economic environment can generate substantial change in distributive outcomes. Second, among the political resources available to citizens, the right to vote is among the most equally distributed. Access to many other mechanisms of political leverage - such as lobbying, campaign contributions, political activism, and structural power (i.e., capital's exit threat) — tends to be strongly and

5. To be clear, in conceptualizing these three types of responses, we are characterizing three possible patterns of observed electoral behavior rather than a set of motivations or attitudes. In referring to a "demand" for inequality, for instance, we are characterizing a particular pattern of electoral behavior that effectively creates incentives for elites to "supply" more inequality. We intend to make no claim about conscious citizen support for policies that redistribute toward the rich. positively correlated with income. Where less affluent citizens effectively "surrender" their economic votes, incumbents face little countervailing pressure to resist the policy demands of the most economically and politically privileged. An electorate indifferent to inequality at the top is more likely to get it.

\section{Cross-national expectations}

Are we likely to observe class-biased economic voting outside the United States? More specifically, are conditions favorable to CBEV likely to operate more generally in advanced democracies? Our cross-national expectations will likely depend on the theoretical mechanism that is presumed to underlie this pattern of voting behavior.

Bartels's analysis of the United States suggests that classbiased information may be an important element in the CBEV pattern. He points to evidence that the perverse pattern of economic voting he uncovers may stem from biases in the informational environment in which election campaigns are fought. First, drawing on ANES data since 1980, Bartels (2008, 116, n. 19) reports a modest association between subjective evaluations of the national economy and election-year income gains and losses for households at the 95th percentile, controlling for mean income growth. This implies that voters' economic judgments improve with the changing fortunes of the affluent, over and above broader economic developments. Second, in an analysis of campaign spending, he finds suggestive evidence that election year income gains at the 95th percentile are modestly correlated with the incumbent party's net campaign spending advantage, again controlling for average growth (Bartels 2008, 117-18). The campaign messages of the party in power ap- 
pear to be broadcast at higher relative volume when the most affluent have fared better. ${ }^{6}$

While America's "unequal democracy" may be a most likely case for the generation of class-biased information about the economy and politics, particularly given the role of private money in the country's electoral politics, there are reasons to expect class biases in information across capitalist democracies. Given modest levels of political knowledge and interest, citizens typically rely on salient cognitive shortcuts (or heuristics) in arriving at political judgements (Lau and Redlawsk 2006; Sniderman, Brody, and Tetlock 1991). In the economic domain, accordingly, voters are likely to draw inferences about the economy, implicitly or explicitly, from visible, easy-to-interpret economic indicators (Conover, Feldman, and Knight 1986), which are often strongly correlated with the welfare of the rich. Consider, for instance, the difference in visibility between stock market performance and corporate earnings (highly correlated with the incomes of the top 5\%) and changes in median wages (highly correlated with the incomes of low- and middleincome households). At the same time, common features of the political economy of media systems in capitalist democracies - including ownership of media outlets by major corporations and wealthy families - may generate systematic class biases in economic news. Media biases may also stem from the reliance of reporters on authoritative sources (Schudson 2002) that offer an elite-centered perspective on economic conditions (e.g., that of bank economists, central bankers, and investment analysts; see Doyle 2002). The result is likely to be an informational environment that systematically overrepresents the economic experiences and interests of the most affluent. ${ }^{7}$

A second and related question goes to CBEV's dynamics. Voting patterns driven by class differentials in material resources would seem to threaten deepening inequality across income groups over time. If voters disproportionately reward politicians for producing income gains at the top, then incumbents are incentivized to further enrich the most affluent. As inequality increases, the rich will in turn deploy their mounting resource advantages to further tilt the electoral playing field in their favor (see Schattschneider 1960), amplifying class-biased voting patterns. CBEV may thus yield a self-reinforcing process that generates mounting

6. With the partisanship of the incumbent administration and average growth controlled, however, the effect falls just below conventional levels of statistical significance.

7. A large literature details the role of the mass media in shaping political attitudes and perceptions, including perceptions of economic conditions (Hetherington 1996; Nadeau et al. 1999; Sanders and Gavin 2004; Soroka 2006). "winner-take-all" dynamics over time (Hacker and Pierson 2011; see also Rosset, Giger, and Bernauer 2013).

On the other hand, as inequality increases, there are likely to be limits to voters' tendency to elide the interests of the rich with the interests of the rest. As mounting income shares flow to the rich, the distribution of resources is increasingly likely to draw media attention, while parties and candidates will find it increasingly useful to prime distributional grievances and to frame economic outcomes and issues in distributional terms (Evans and Tilley 2012; Meltzer and Richard 1981; Tavits and Potter 2014). Lower- and middle-income voters, in turn, are increasingly likely to attend to and to distinguish between signs of enrichment at the top and indicators of broadly shared economic benefits. In other words, while the mass psychology of economic accountability may not always be characterized by class-based concerns, distributional criteria may well become activated as objective material outcomes tilt against the interests of the nonaffluent. Class-biased voting patterns thus may be characterized by self-limiting rather than self-reinforcing dynamics.

In the next two sections of this article, we bring comparative evidence to bear on these two questions. First, is CBEV found broadly in advanced democracies? We test for evidence of CBEV by replicating Bartels's individual-level analysis in three other advanced democracies and by examining income dynamics and aggregate voting patterns across a much larger set of OECD countries. Second, to the extent that cross-national evidence for CBEV emerges, we then examine whether it is prone to a self-reinforcing or self-limiting logic. We do so by exploiting our large crossnational sample of elections to examine whether $\mathrm{CBEV}$ effects strengthen or weaken as economic resources become increasingly concentrated at the top.

\section{ELECTION-STUDY EVIDENCE}

We begin by looking for evidence of CBEV in electionstudy data drawn from four advanced democracies. While our focus is comparative, we first attempt to replicate and extend Bartels's original test in the US case. We then conduct parallel analyses on data from Sweden, the United Kingdom, and Canada. For each country, we bring together data spanning at least five decades. We selected these countries for two reasons. First, they have relatively long time series of national election studies, allowing us to maximize inferential leverage, which hinges on the number of elections in the analysis. Second, we have sought to look for evidence of CBEV in political-economic and cultural settings relatively similar to the United States (Canada and the United Kingdom) as well as in a setting in which such a finding would be rather surprising - solidaristic Sweden. 


\section{Data and specification}

We test for class-biased economic voting by estimating a probit model regressing individual-level vote choice on objective measures of pre-election income growth and a pair of controls. We capture the dependent variable, vote choice at the individual level (Vote_Incumbent), with reported vote measures collected by each country's national election studies. ${ }^{8}$ Those casting a ballot for the party of the incumbent president or prime minister are coded 1 , while all others are coded $0 .{ }^{9}$ We confine the analysis to voters in order to avoid confounding possible voter mobilization effects with the conversion processes implied by economic voting theory.

In our primary specifications, our key explanatory variables are measures of top-income growth and of growth in mean income. Following Bartels (2008), our top-income measure in the present analyses refers to the highest-earning $5 \%$ of households; we examine the use of other top-income definitions in the broader comparative analyses in the next section. We test for CBEV not just for the electorate in the aggregate but, following Bartels (2008), also for the bottomand middle-income terciles. In analyses for low- and middleincome groups, we also probe for robustness by estimating secondary models that control for income growth at the bottom and middle of the income distribution, respectively, rather than for growth in population mean income. ${ }^{10}$

Based on our theoretical model of electoral reponsiveness to inequality (discussed above), we seek to use data that capture growth in the mean incomes of the relevant income groups, wherever available. ${ }^{11}$ For country time periods in which data on the mean incomes of income groups are unavailable or of low quality, we substitute measures of growth rates at the relevant percentiles. ${ }^{12}$

Where available, we use measures of disposable income, as past work indicates the strongest electoral impact of this income measure (e.g., Hibbs 2000; Tufte 1978). Again, data

8. For Canada in 1972, we must substitute a measure of vote intention from the pre-election second wave of this study.

9. Restricting the exercise of economic accountability to the party of the incumbent prime minister is consequential only in the case of Sweden, where multiparty governments are the norm. This coding practice follows Duch and Stevenson (2008).

10. As income growth data are unavailable for terciles, we approximate income growth for the bottom third of voters using mean growth for the bottom $40 \%$, where available, or growth at the 20th percentile, otherwise. Analogously, we approximate income growth for the middle tercile using growth in the mean income of the middle quintile, where available; otherwise we use either growth at the 50th percentile, if available, or growth in the average of the 40th and 60th percentiles.

11. Bartels (2008) measures income growth for households at the 95th percentile of the income distribution.

12. Results reported in section D of the appendix show that P95 and mean of the top-5\% measures yield similar findings in most analyses. availability in some cases forces us to use an alternative measure, typically total pre-tax income. Wherever possible, we report results using alternative income measures in the appendix (section D). We summarize the income measures used for each country here and provide further details in the appendix (section A.1).

For the United States, we use total family income as our income concept, as disposable income measures are not available for the top-5\% or other quantiles. We measure mean real total family income for the population using data from the Bureau of Economic Analysis and the Census Bureau. We draw measures of growth in the mean incomes of the top-5\% and relevant quintiles from the US Census Bureau, allowing analyses of the period 1968-2012.

For Sweden, we use disposable income data from 1980 onward provided by Statistics Sweden. While we employ measures of income group means for the quintiles, data quality issues limit us to 95th percentile threshold values for capturing top-income growth. ${ }^{13}$ For elections prior to 1980, we draw from Sweden Statistical Yearbook data on population numbers within bands of total taxable, pre-tax income. We use these numbers to estimate quintile and 95th percentile threshold incomes by linear interpolation between the boundaries of the income bands. ${ }^{14}$

For the United Kingdom, we employ population mean, quintile threshold, and 95th percentile threshold real disposable income growth data from the Institute for Fiscal Studies (Cribb et al. 2013). ${ }^{15}$ Measures of the mean incomes of income quantiles are unavailable for this case.

For Canada, we draw our income measures from different sources for the earlier and later periods of the sample. From 1976 onward, Statistics Canada provides data on mean real after-tax income and real after-tax income by quintile. ${ }^{16}$ From 1982 onward, we are also able to use Statistics Canada data on the mean of top-5\% incomes. ${ }^{17}$ Due to the rather short time series that this yields, we supplement this with data from the World Top Incomes Database (Alvarez et al. 2012). This latter measure captures the mean

13. We discuss reliability problems with the top-5\% mean income measure in the appendix (section A.1.3).

14. This procedure is described more fully in section A.1.4 of the appendix.

15. Specifically, we use the spreadsheet entitled "Inequality and Poverty Spreadsheet," which accompanies the IFS report. We focus on the "before housing costs" series for consistency with the other countries studied here. The underlying data for the spreadsheet are drawn from the government's Family Expenditure Survey (FES) and the Family Resources Survey (FRS).

16. This information is provided in their tables 202-0202 and 2020701.

17. This information is provided in their table 204-0001. 
1082 / Inequality and Electoral Accountability Timothy Hicks, Alan M. Jacobs, and J. Scott Matthews

of top-5\% total, rather than after-tax, income. However, as we show in the appendix, the WTID data correlate very highly with those from Statistics Canada (see appendix figs. 1 and 2) and also do not drive our inferences for the models in which they are used (see appendix table D.10).

In light of findings on the particular importance of the election year economy in shaping the vote (Achen and Bartels 2004; Bartels 2008; Fair 1978; Healy and Lenz 2014; Kiewiet 1983), we construct measures of income growth to correspond as closely as possible to the year prior to the election. All growth measures are constructed as a weighted average of growth in the election year and in the prior year, where the weights are simply the fraction of the 12 months prior to that election date that falls in each calendar year. Table 2 provides a key to the notation that we adopt in order to distinguish among the measures underlying our several income growth variables.

We follow Bartels (2008) in including two controls in the models. First, we include a measure capturing whether a respondent identifies with the party of the president or prime minister (ProPartyID), as appropriate. ${ }^{18}$ Adding this covariate - a strong predictor of vote choice in each of the four countries - leads to cleaner estimates of the effects of election year income changes. ${ }^{19}$ Second, we control for the number of consecutive years that the party of the president or the prime minister has held that post (Tenure), ${ }^{20}$ with the aim of capturing the effects of the electoral costs of ruling. Whereas Bartels (2008) includes party tenure as a linear term, we take the $\log$ of this variable ( $\log ($ Tenure)) on the expectation that the marginal electoral costs of additional years in office are likely diminishing in political contexts in which single parties have governed continuously for decades at a time (e.g., Sweden). In the appendix (section D), we demonstrate that our inferences for the four countries are not driven by this adjustment but that model fit tends to be improved.

In order to estimate CBEV effects for low- and middleincome groups, respondent income is coded into approximate terciles for each country-year, following Bartels (2008). We assign those at or below the $33 \mathrm{rd}$ percentile of the study sample to the "low" income category, those above the 33rd and at or

18. For the United States, we use the standard seven-point scale (ranging from -1 to 1 ). For Sweden, the United Kingdom, and Canada, we use a simple dummy variable.

19. In the appendix (section B.2), we provide a more detailed discussion of the inclusion of this covariate. We note, further, that the aggregate-level results reported in section 4 are based on models without controls for party identification.

20. In calculating these values, we exclude any intervening caretaker governments.
Table 2. Definitions of Notation Used in Income Growth Variable Label Superscripts to Indicate Which Type of Measure Is Employed

\begin{tabular}{ll} 
Variable Label & \multicolumn{1}{c}{ Description } \\
\hline T5M & Top-5\% mean \\
P95 & 95th percentile value \\
T5 & A mixture of T5M, where available, \\
& and P95, otherwise \\
M & Population mean \\
Q1 - 2M & First and second quintile (i.e., bottom-40\%) \\
& mean \\
P20 & 20th percentile value \\
Q1 - 2 & A mixture of Q1 - 2M, where available, \\
& and P20, otherwise \\
Q3M & Middle quintile mean \\
P40 - 60 & Average of 40th and 60th percentile values \\
P50 & 50th percentile value \\
Q3 & A mixture of Q3M, where available, \\
& and P40 - 60, otherwise
\end{tabular}

below the 66th percentile to the "middle" category, and all others to the "high" income category. ${ }^{21}$ The precise measure of respondent income varies somewhat across countries and within countries over time. In general, we employ election survey measures of self-reported, pre-tax household income. This measure is available for most US, British, ${ }^{22}$ and Canadian surveys. For Sweden, we employ, where available, income measures gathered by the Swedish National Election Studies program from respondent tax records, and otherwise we use self-reports embedded in the election surveys. Finally, for married respondents in some early British and Swedish surveys, it was necessary to construct household income measures by combining separate income reports for husbands and wives.

Drawing on the above measures, we estimate as our primary specification probit models of the general form:

$$
\begin{aligned}
\text { Vote_Incumbent }_{i, t}= & \beta_{0}+\beta_{1} \cdot \log \text { Tenure }_{t} \\
& +\beta_{2} \cdot \text { ProPartyID }_{i, t}+\beta_{3} \cdot \text { Growth }_{t}^{\mathrm{M}} \\
& +\beta_{4} \cdot \text { Growth }_{t}^{\mathrm{Top} 5}+\epsilon_{i, t},
\end{aligned}
$$

where $i$ indexes an individual voter, $t$ indexes an election, and Top5 is replaced with a superscript label indicating the precise top income measure used, following table 2. In our

21. We exclude from the analysis those with missing values for income, in keeping with Bartels (2008, 72, n. 17)

22. The 1983 British Election Study substituted a measure of the respondent's perception of how their household income compared with the national average for the traditional household income indicator. We are, therefore, forced to exclude this wave from any analyses conditioning on respondent income. 
secondary specification, estimated for low- or middle-income voters, Growth ${ }_{t}^{\mathrm{M}}$ is replaced by a measure of income growth at the bottom or middle of the income scale.

\section{Results}

We begin by summarizing the joint distribution of our two key explanatory variables: income growth among the top 5\% of earners (Growth ${ }^{\mathrm{Top} 5}$ ) and mean income growth $\left(\right.$ Growth $\left.^{\mathrm{M}}\right)$. Figure 1 displays bivariate scatter plots and reports correlation coefficients for these two variables for each of the four countries, with solid circles denoting election year observations (those included in our analyses) and hollow circles denoting non-election year observations. The diagonal line in each plot

A

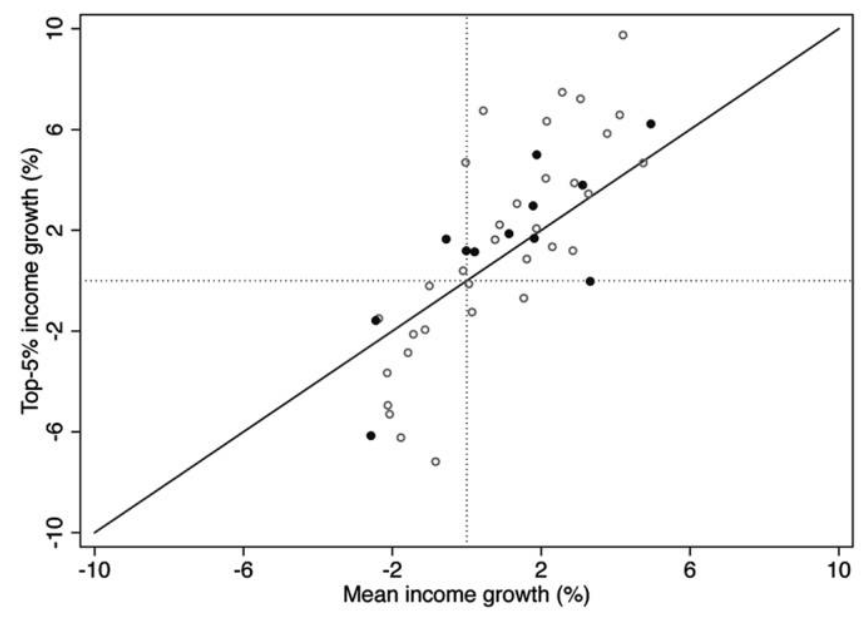

United States: $1967-2013\left(\rho^{a}=0.80\right.$ or $\left.\rho^{e}=0.79\right)$

C

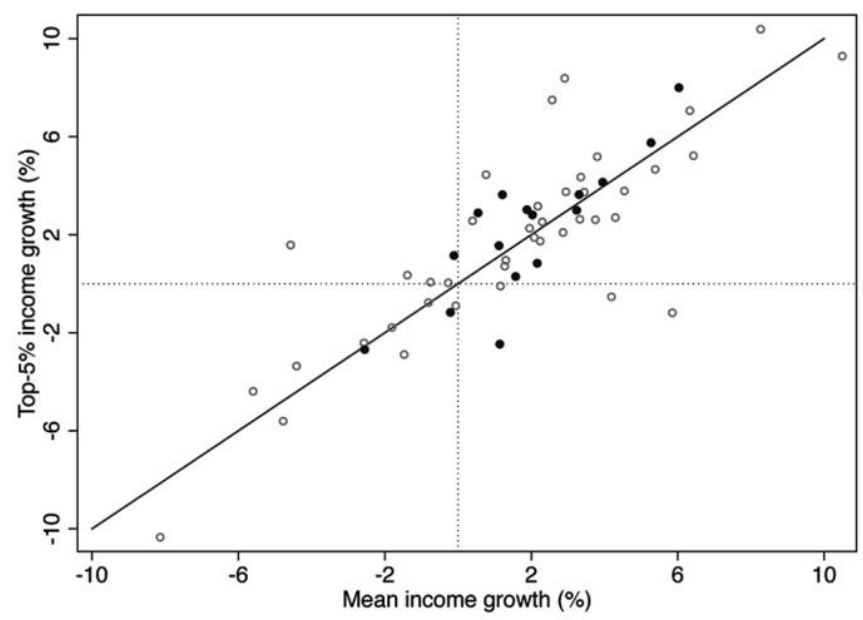

Sweden: $1961-2011\left(\rho^{a}=0.83\right.$ or $\left.\rho^{e}=0.84\right)$ represents equality between mean growth and top-end growth, implying no change in relative income shares between the richest 5\% and the remaining 95\%. Observations above the line imply an increase in the income shares received by the top $5 \%$, whose incomes have grown faster than the rest. Observations below the line imply a reduction in inequality, as the incomes of the bottom 95\% have grown faster than incomes at the top. Unsurprisingly, the two growth rates are positively correlated across all four countries, especially so in Sweden and the United Kingdom. Importantly, however, we see that, in each country, there has been substantial variation in the distribution of aggregate gains. In each country, incumbent parties have sometimes presided over election year

B

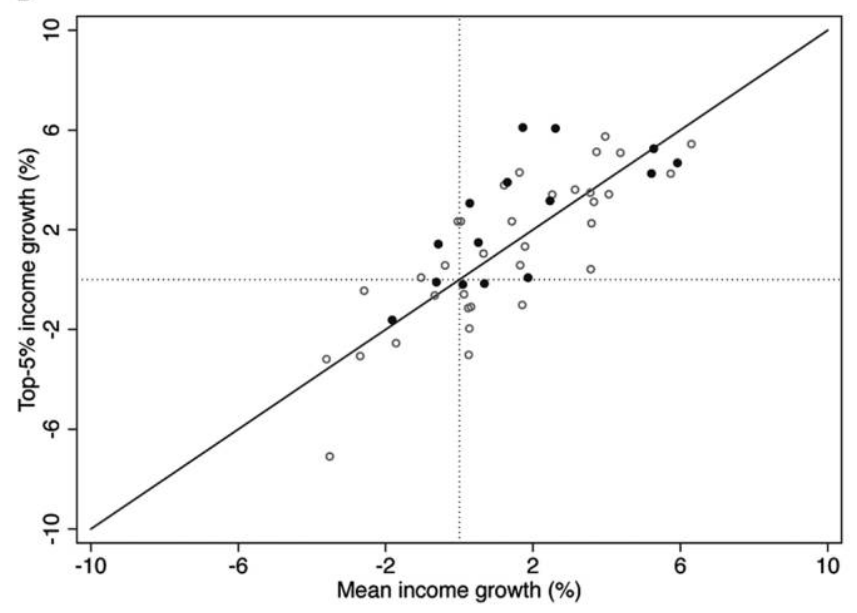

Canada: 1968-2011 $\left(\rho^{a}=0.79\right.$ or $\left.\rho^{e}=0.71\right)$

D

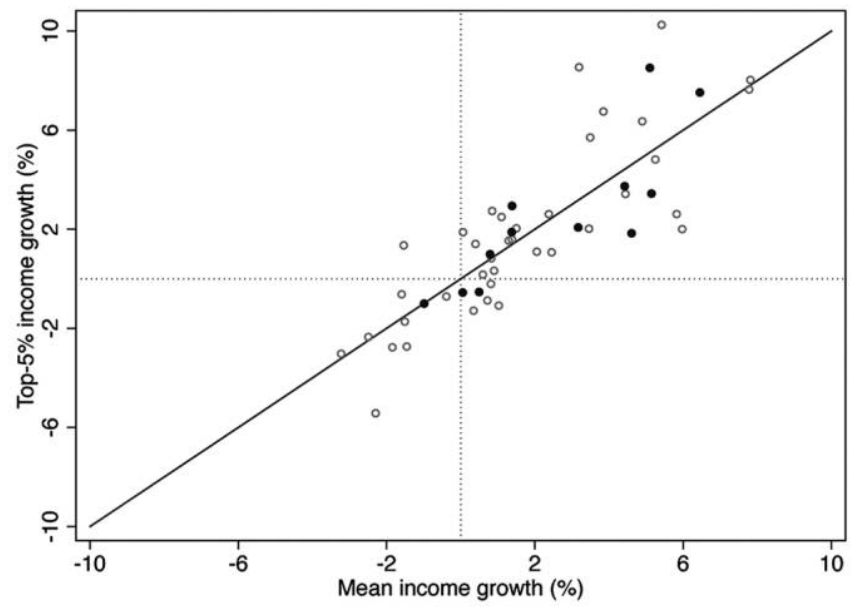

United Kingdom: 1962-2011 ( $\rho^{a}=0.83$ or $\left.\rho^{e}=0.84\right)$

Figure 1. Scatter plots of mean income growth (Growth ${ }^{\mathrm{M}}$ ) and top income growth (Growth ${ }^{\top 5}$ ) for four countries, the United States, Canada, Sweden, and the United Kingdom. Solid circles denote election year observations; hollow circles denote non-election year observations. Diagonal lines represent equality of mean and top income growth rates; $\rho^{\alpha}$ and $\rho^{e}$ denote correlation coefficients for all and for election years, respectively. We exclude the 1993 (non-election year) observation for the United States as a clear outlier driven by a change in the underlying survey response categories. See footnote 23 of the Census Bureau's "Historical Income Tables Footnotes" for details. 
economies that delivered disproportionate gains to the rich, and sometimes over relative election year gains for the bottom $95 \%$. How have voters responded to these varying distributional records? Has the electorate - and, in particular, have lower- and middle-income voters - punished inequality-increasing incumbents relative to those who spread economic gains more broadly?

We test for class-biased responsiveness in the four countries' electorates using the data and model specifications described in the previous section. We note that, in all models, the effective $N$ is the number of elections, since inferences derive from variation in rates of income growth (for various groups) across election years. The number of elections analyzed in each country is necessarily constrained by the length of the national election-study series. For full-sample estimates, our election $N$ is 12 for the United States, 15 for Canada and Sweden, and 12 for the United Kingdom. In each model, the principal estimate of interest is the effect of income growth among the top $5 \%$ of earners.

Table 3 presents the results of models that replicate Bartels's analysis of the United States fairly closely. ${ }^{23}$ Following Bartels, we estimate probit models with standard errors clustered at the election level. Our analysis differs from Bartels's in three ways. First, we include the 2008 and 2012 elections. Second, for greater consistency with our CBEV conceptualization (especially to better capture income dynamics between groups), we measure growth in the mean income of the top 5\% rather than growth at the 95th percentile. ${ }^{24}$ Third, since US top-income measures capture pre-tax total family income, we employ the same income concept when measuring mean income (rather than mean disposable personal income, as in Bartels's analysis).

Model 1, estimated on the full sample of respondents for each wave, demonstrates that Bartels's aggregate CBEV finding persists through the two Obama elections (and survives the changes in measurement strategies). In the aggregate, the American electorate over the 1968-2012 period displays a strong demand for inequality, captured by the large and highly significant coefficient on Growth ${ }^{\mathrm{TSM}}$. We note that, by comparison, the electorate's response to mean growth (controlling for top-end growth) is small and statistically insignificant.

The next four specifications build on this result by estimating models separately for those in the two lower income terciles. Model 2 shows that the full-sample results are replicated in the bottom income tercile. We observe a strong

23. Coefficients on our income growth variables are approximately two orders of magnitude larger than Bartels's because our growth rates are not multiplied by 100 as are his.

24. We show results using percentile threshold measures, instead of means, in the appendix, table D.1. Findings are unaffected. demand for inequality among low-income US voters, a systematic tendency for low-income Americans to reward incumbent parties that preside over a redistribution of income growth to the top $5 \%$. As we see in model 3, our secondary specification, this effect is robust to controlling for growth in the lower portion of the income scale rather than population mean growth. ${ }^{25}$ In model 4 , we see a clear demand for inequality among middle-income voters. In model 5, we see that this effect of top-income growth persists (and, in fact, grows) if we control for growth in the mean income of the middle quintile rather than population mean growth. In summary, with an updated sample, the core features of CBEV in the United States, both in the aggregate and for low- and middle-income voters, remain clear.

We now turn to the search for evidence of CBEV beyond the United States, following the same sequence of specifications as for the American replication. We first examine the British case, with the results presented in table 4 . The British electorate displays a quite strong positive demand for inequality. Model 1 reveals that, in the aggregate, British voters reward income growth in the top $5 \%$, indicated by the positive and significant coefficient estimate for Growth ${ }^{\mathrm{P} 95}$. A demand for inequality is also precisely estimated among middle-income earners, in models 4 and 5, controlling for either population mean or middle-income growth. Finally, among lower-income voters the pattern is mixed: controlling for mean growth (model 2) produces a Growth ${ }^{\mathrm{P} 95}$ estimate that is statistically significant (at the 99\% level) and roughly the size of that applying to middleincome voters; controlling for first-quintile growth (model 3) suggests voters in the bottom income tercile are indifferent to inequality.

The Swedish results in table 5 also yield substantial evidence of class-biased economic voting. In model 1, estimated for the whole electorate, the estimated coefficient on topincome growth $\left(\right.$ Growth ${ }^{\mathrm{P} 95}$ ) is statistically significant and, moreover, is around 20 times larger than the (insignificant) estimated coefficient for mean growth (Growth ${ }^{\mathrm{M}}$ ). Evidence of a demand for inequality is also clear among the bottom third of Swedish earners. In model 2, controlling for mean income growth, the positive effect of top-income growth is significant at the 95\% level. Similarly, in model 3, which controls for income growth among the low-income group rather than mean income growth, the effect of top-income growth on low-income voters is positive and significant above the $99 \%$ level. ${ }^{26}$ The results for models 4 and 5 suggest

25. Table D.2 of the appendix reports similar results when controlling for income growth in the 20th percentile income threshold.

26. Table D.6 of the appendix reports similar results when controlling for income growth in the 20th percentile income threshold. 
Table 3. United States: Probit Estimates of Coefficients for Predictors of Voting for the Incumbent Party in American Presidential Elections (1968-2012)

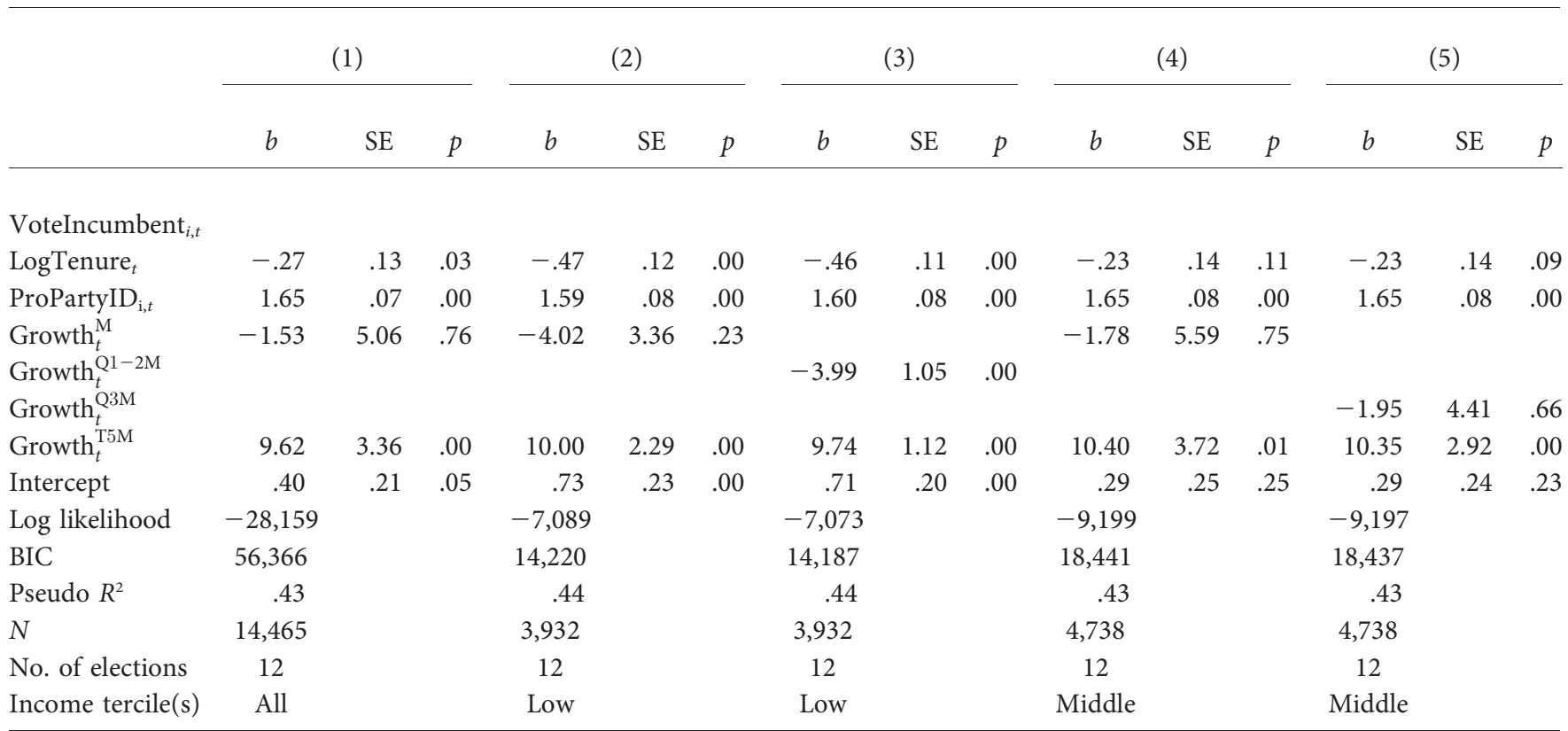

Note. Standard errors are clustered by election.

a less clear-cut inference for middle-income Swedish voters, somewhere between a demand for inequality and indifference. In model 4 , the coefficient on Growth ${ }^{\mathrm{P} 95}$, controlling for mean growth, is approximately equal in magnitude to that estimated for lower-income voters, although less precisely estimated. Model 5, however, implies that middle-income earners are indifferent to inequality: controlling for middlequintile growth, the coefficient on Growth ${ }^{\mathrm{P} 95}$ is halved in size (relative to model 4) and far from statistical significance.

Turning, finally, to the Canadian case, the results in table 6 provide weaker evidence of $\mathrm{CBEV}$ effects. As a whole, the Canadian electorate displays a fairly clear indifference to in-

Table 4. United Kingdom: Probit Estimates of Coefficients for Predictors of Voting for the Incumbent Party in British Parliamentary Elections (1964-2010)

\begin{tabular}{|c|c|c|c|c|c|c|c|c|c|c|c|c|c|c|c|}
\hline & \multicolumn{3}{|c|}{$(1)$} & \multicolumn{3}{|c|}{ (2) } & \multicolumn{3}{|c|}{ (3) } & \multicolumn{3}{|c|}{ (4) } & \multicolumn{3}{|c|}{ (5) } \\
\hline & $b$ & SE & $p$ & $b$ & SE & $p$ & $b$ & SE & $p$ & $b$ & SE & $p$ & $b$ & SE & $p$ \\
\hline VoteIncumbent $_{i, t}$ & & & & & & & & & & & & & & & \\
\hline LogTenure $_{t}$ & -.28 & .06 & .00 & -.48 & .07 & .00 & -.52 & .07 & .00 & -.28 & .07 & .00 & -.29 & .06 & .00 \\
\hline ProPartyID ${ }_{i, t}$ & 2.64 & .06 & .00 & 2.69 & .10 & .00 & 2.69 & .10 & .00 & 2.60 & .08 & .00 & 2.60 & .08 & .00 \\
\hline Growth $_{t}^{\mathrm{M}}$ & -8.33 & 2.48 & .00 & -9.92 & 2.94 & .00 & & & & -7.73 & 2.81 & .01 & & & \\
\hline Growth $_{t}^{\mathrm{Q} 1-2 \mathrm{M}}$ & & & & & & & -6.43 & 1.58 & .00 & & & & & & \\
\hline Growth $_{t}^{\mathrm{Q} 3 \mathrm{M}}$ & & & & & & & & & & & & & -5.06 & 2.00 & .01 \\
\hline Growth $_{t}^{\mathrm{T} 5 \mathrm{M}}$ & 4.45 & 2.30 & .05 & 5.07 & 1.92 & .01 & -.53 & .94 & .57 & 5.43 & 1.82 & .00 & 3.95 & 1.99 & .05 \\
\hline Intercept & -.71 & .12 & .00 & -.33 & .19 & .08 & -.19 & .20 & .36 & -.74 & .19 & .00 & -.77 & .15 & .00 \\
\hline Log likelihood & $-30,032$ & & & $-7,063$ & & & $-7,056$ & & & $-8,186$ & & & $-8,191$ & & \\
\hline BIC & 60,115 & & & 14,170 & & & 14,156 & & & 16,416 & & & 16,427 & & \\
\hline Pseudo $R^{2}$ & .54 & & & .58 & & & .58 & & & .54 & & & .54 & & \\
\hline$N$ & 28,402 & & & 7,374 & & & 7,374 & & & 7,435 & & & 7,435 & & \\
\hline$N$ of elections & 12 & & & 11 & & & 11 & & & 11 & & & 11 & & \\
\hline Income tercile(s) & ) All & & & Low & & & Low & & & Middle & & & Middle & & \\
\hline
\end{tabular}

Note. Standard errors are clustered by election. 
1086 / Inequality and Electoral Accountability Timothy Hicks, Alan M. Jacobs, and J. Scott Matthews

Table 5. Sweden: Probit Estimates of Coefficients for Predictors of Voting for the Incumbent Party in Swedish Parliamentary Elections (1968-2010)

\begin{tabular}{|c|c|c|c|c|c|c|c|c|c|c|c|c|c|c|c|}
\hline & \multicolumn{3}{|c|}{ (1) } & \multicolumn{3}{|c|}{ (2) } & \multicolumn{3}{|c|}{ (3) } & \multicolumn{3}{|c|}{ (4) } & \multicolumn{3}{|c|}{ (5) } \\
\hline & $b$ & SE & $p$ & $b$ & $\mathrm{SE}$ & $p$ & $b$ & SE & $p$ & $b$ & $\mathrm{SE}$ & $p$ & $b$ & SE & $p$ \\
\hline VoteIncumbent $_{i, t}$ & & & & & & & & & & & & & & & \\
\hline LogTenure $_{t}$ & .25 & .05 & .00 & .23 & .04 & .00 & .18 & .05 & .00 & .35 & .07 & .00 & .29 & .08 & .00 \\
\hline ProPartyID $\mathrm{I}_{\mathrm{i}, t}$ & 2.62 & .10 & .00 & 2.56 & .11 & .00 & 2.55 & .11 & .00 & 2.59 & .14 & .00 & 2.58 & .14 & .00 \\
\hline Growth $_{t}^{\mathrm{M}}$ & .26 & 4.16 & .95 & 1.16 & 2.93 & .69 & & & & 1.22 & 4.79 & .80 & & & \\
\hline Growth $_{t}^{\mathrm{Q} 1-2 \mathrm{M}}$ & & & & & & & 3.57 & 1.17 & .00 & & & & & & \\
\hline Growth $_{t}^{\text {Q3M }}$ & & & & & & & & & & & & & 7.07 & 4.71 & .13 \\
\hline Growth $_{t}^{\mathrm{T} 5 \mathrm{M}}$ & 5.18 & 2.71 & .06 & 4.31 & 2.04 & .03 & 4.36 & 1.14 & .00 & 4.59 & 2.68 & .09 & 2.25 & 2.74 & .41 \\
\hline Intercept & -1.37 & .15 & .00 & -1.41 & .11 & .00 & -1.33 & .12 & .00 & -1.50 & .20 & .00 & -1.39 & .19 & .00 \\
\hline Log likelihood & $-49,678$ & & & $-16,513$ & & & $-16,478$ & & & $-16,807$ & & & $-16,754$ & & \\
\hline $\mathrm{BIC}$ & 99,407 & & & 33,070 & & & 33,002 & & & 33,658 & & & 33,553 & & \\
\hline Pseudo $R^{2}$ & .28 & & & .28 & & & .28 & & & .30 & & & .31 & & \\
\hline$N$ & 22,690 & & & 7,797 & & & 7,797 & & & 7,830 & & & 7,830 & & \\
\hline No. of elections & 15 & & & 15 & & & 15 & & & 15 & & & 15 & & \\
\hline Income tercile(s) & All & & & Low & & & Low & & & Middle & & & Middle & & \\
\hline
\end{tabular}

Note. Standard errors are clustered by election.

equality, indicated, in model 1 , by the statistically insignificant coefficient on Growth ${ }^{\mathrm{TSM}}$. The coefficient estimates for model 2 and model 4 estimated for lower-income and middle-income voters, respectively - also reveal the indifference to inequality pattern when controlling for mean growth. Our secondary specifications - in model 3 and model 5-provide stronger suggestions of a demand for inequality. However, due to data constraints, these estimates are based on smaller samples of elections and results reported in the appendix (table D.9) indicate that our primary specification is to be preferred for these smaller samples.

We provide a qualitative overview of our inferences from the election-study data in table 7. Overall, the balance of the evidence in the national election studies suggests that, across

Table 6. Canada: Probit Estimates of Coefficients for Predictors of Voting for the Incumbent Party in Canadian Parliamentary Elections (1965-2011)

\begin{tabular}{|c|c|c|c|c|c|c|c|c|c|c|c|c|c|c|c|}
\hline & \multicolumn{3}{|c|}{$(1)$} & \multicolumn{3}{|c|}{ (2) } & \multicolumn{3}{|c|}{ (3) } & \multicolumn{3}{|c|}{ (4) } & \multicolumn{3}{|c|}{ (5) } \\
\hline & $b$ & SE & $p$ & $b$ & SE & $p$ & $b$ & SE & $p$ & $b$ & SE & $p$ & $b$ & SE & $p$ \\
\hline VoteIncumbent $_{i, t}$ & & & & & & & & & & & & & & & \\
\hline LogTenure $_{t}$ & -.10 & .06 & .12 & -.00 & .05 & .98 & -.00 & .06 & .97 & -.06 & .09 & .54 & -.14 & .07 & .03 \\
\hline ProPartyID ${ }_{\mathrm{i}, t}$ & 1.94 & .14 & .00 & 2.03 & .21 & .00 & 2.04 & .18 & .00 & 2.00 & .15 & .00 & 1.95 & .16 & .00 \\
\hline Growth $_{t}^{\mathrm{M}}$ & 8.07 & 3.40 & .02 & 6.89 & 2.68 & .01 & & & & 10.22 & 4.59 & .03 & & & \\
\hline Growth $_{t}^{\mathrm{Q} 1-2 \mathrm{M}}$ & & & & & & & 2.76 & 2.59 & .29 & & & & & & \\
\hline Growth $_{t}^{\mathrm{Q} 3 \mathrm{M}}$ & & & & & & & & & & & & & 8.21 & 5.51 & .14 \\
\hline Growth $_{t}^{\mathrm{T} 5 \mathrm{M}}$ & 3.13 & 3.15 & .32 & 2.07 & 2.95 & .48 & 6.45 & 3.18 & .04 & 2.17 & 3.37 & .52 & 3.39 & 2.07 & .10 \\
\hline Intercept & -1.05 & .14 & .00 & -1.22 & .13 & .00 & -1.28 & .21 & .00 & -1.15 & .17 & .00 & -.99 & .12 & .00 \\
\hline Log likelihood & $-46,890$ & & & $-11,417$ & & & $-7,062$ & & & $-14,824$ & & & $-9,048$ & & \\
\hline BIC & 93,832 & & & 22,880 & & & 14,168 & & & 29,694 & & & 18,140 & & \\
\hline Pseudo $R^{2}$ & .33 & & & .35 & & & .37 & & & .33 & & & .34 & & \\
\hline$N$ & 31,623 & & & 8,794 & & & 6,832 & & & 9,951 & & & 7,527 & & \\
\hline No. of elections & 15 & & & 15 & & & 11 & & & 15 & & & 11 & & \\
\hline Income tercile(s) & All & & & Low & & & Low & & & Middle & & & Middle & & \\
\hline
\end{tabular}

Note. Standard errors are clustered by election. 
a range of political-economic settings, governments face significant electoral incentives to concentrate economic gains among the rich. In none of the four countries, moreover, do we find a hint of evidence that voters - in the aggregate, at the bottom, or in the middle-sanction incumbents for redistributing income toward the very top of the income scale.

We also emphasize an important feature of the model interpretation. There might, of course, be nothing irrational about non-rich voters rewarding incumbents for income growth at the top to the extent that their own fortunes are correlated with those of the rich. The models estimated here, however, are specified such that the results cannot be a consequence of "correlated fortunes." In the primary specification, any rewards for generally positive outcomes are captured by the mean income growth coefficient. Likewise, in the secondary specifications, rewards for income growth at particular points lower down the income scale are captured by the coefficients on controls for bottom- and middle-income growth (for, respectively, the low-income and middle-income samples). Thus, the parameter estimates for the top-income growth variable reflect a reward to incumbents strictly for faster income growth among the top 5\%, above and beyond any rewards for faster mean growth (primary specification) or for faster growth among lower- or middle-income voters (secondary specifications). (We formalize this point in section B.1 of the appendix.)

To provide a sense of substantive effect sizes, in figure 2, we plot estimates for each country of the average marginal effects of both top-income and mean-income growth on the probability of a vote for the incumbent party, among all, low-income, and middle-income voters. All effect estimates correspond to a one standard deviation increase in the measures. While CBEV effects are substantively important in Sweden, the United Kingdom, and the United States, the plots reveal notable crossnational variation: the average marginal effect of an extra standard deviation of top-income growth, holding mean growth fixed, ranges from roughly 2 points in incumbent party support in the United Kingdom to approximately 6 points in the
United States. By contrast, variation in top-income growth effects across income groups within countries appears quite modest. The effects of mean income growth (holding topgrowth constant), while not of direct interest here, exhibit significant cross-country variation and, again, fairly incidental within-country variation, with the partial exception of Canada. The relative sizes of the top-growth and mean growth effects are not of direct relevance for assessing the demand for inequality, which is captured strictly by the Growth ${ }^{\text {Top5 }}$ coefficient in our primary specification. It is nonetheless striking that, in three of the countries, incumbents enjoy no apparent electoral advantage - and in the United Kingdom face a perverse penalty - for boosting mean incomes above and beyond any gains going to the top 5\%. Put differently, only in Canada are there clear electoral rewards for governments that oversee faster income growth for the bottom $95 \%$ of households.

\section{BROADER COMPARATIVE EVIDENCE}

Our election-study analyses allow us to capture the electoral effects of income growth at different quantiles for specific income groups. As a comparative empirical strategy, however, this approach is necessarily limited by the availability of long series of comparable election-study and by-quantile income data across countries. The limited number of election observations also restricts our ability to draw reliable inferences about system-level features that may condition CBEV. In the present section, we expand the sample for analysis by leveraging aggregate election data, as well as mean income and topincome growth measures, that are available for a much larger number of OECD country elections. We conduct time-series, cross-section (TSCS) analyses to examine how top-income growth, controlling for mean growth, affects aggregate vote shares for the party of the incumbent prime minister or president. This approach allows us to assess the presence of CBEV across a much broader swathe of advanced democracies. Further, with over 200 elections in the sample, the increased degrees of freedom permit us to speak to the mod-

Table 7. Summary of Inferences from Election-Study Data about Voter Responsiveness to Inequality across Four Countries

Response to Rising Inequality

\begin{tabular}{llll} 
Country & All Voters & \multicolumn{1}{c}{ Low Income } & \multicolumn{1}{c}{ Middle Income } \\
\hline & & & \\
United States & Demand & Demand & Demand \\
Sweden & Demand & Demand & Demand/indifference \\
United Kingdom & Demand & Demand/indifference & Demand \\
Canada & Indifference & Indifference & Indifference \\
\hline
\end{tabular}



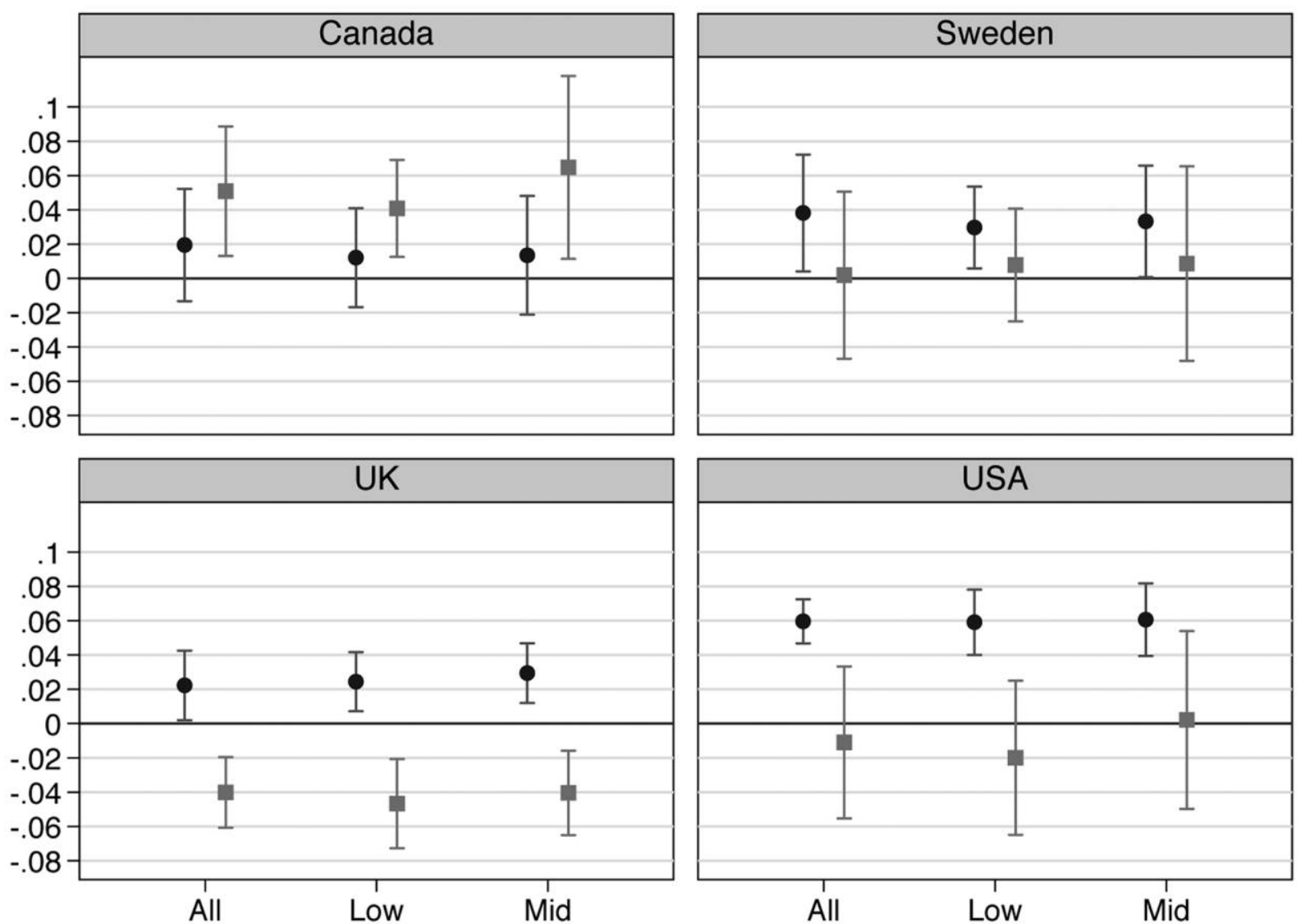

Figure 2. A summary of estimated average marginal effects across countries from models presented in tables $3-6$. Each marker indicates the estimated change in the probability of a vote for the incumbent (together with its $90 \%$ confidence interval), based on a standard deviation change in the respective income-growth measure. Circles denote top-income growth effects, and squares denote mean income growth effects. Effects are estimated while holding all other predictors at their observed values. Effects are shown for the whole electorate (“All”), low-income voters (“Low"), and middle-income voters ("Mid") The latter two sets of estimates derive, respectively, from models 3 and 5 in each results table.

eration of CBEV by inequality itself. By examining whether CBEV effects intensify or wane as greater shares of income go to the highest earners, we can ask whether class-biased electoral processes exhibit self-reinforcing or self-limiting dynamics.

\section{Data and specification}

A large literature has analyzed economic voting patterns at the aggregate (election) level. ${ }^{27} \mathrm{We}$ adopt the influential empirical approach of Powell and Whitten (1993), ${ }^{28}$ who esti-

27. See Nannestad and Paldam (1994) for a summary of the early "VP-function" (vote-popularity function) literature.

28. Powell and Whitten's theoretical contribution was to focus the literature on the importance of "clarity of responsibility" in conditioning economic voting. We bracket this theoretical consideration in the main text, drawing on Powell and Whitten's model specification as an established approach to estimating aggregate-level economic voting models. In the appendix, however, we show that the inferences presented here are robust to controlling for clarity of responsibility. mate aggregate economic vote specifications of the following form:

$\Delta$ VoteShare $_{e, i}=\beta_{0}+\beta_{1} \cdot$ VoteShare $_{e-1, i}+\beta_{\boldsymbol{X}} \cdot \boldsymbol{X}_{t, i}^{\prime}+\epsilon_{i, e}$,

where $e$ indexes elections, $i$ indexes countries, $t$ indexes time, and bold face type indicates vectors. While Powell and Whitten (1993) calculate VoteShare Vo $_{i, \mathrm{i}}$ on the basis of all cabinet-seatholding parties, we focus only on the party of the prime minister or president, reflecting the more recent approach of Duch and Stevenson (2008). Following our specifications for the individual-level analysis, in our key models, we populate $\boldsymbol{X}_{t, i}^{\prime}$ with the log of the number of years that the party holding the prime minister/president post has done so (log $\left(\right.$ Tenure $\left.\left._{i, t}\right)\right)$, election year mean income growth $\left(\right.$ Growth $\left._{i, t}^{\mathrm{M}}\right)$, and election year mean income growth for the top $5 \%$ of the income distribution (Growth ${ }_{i, t}^{\mathrm{T} 5 \mathrm{M}}$ ).

Data for VoteShare Vit, $_{\text {and }} \log \left(\right.$ Tenure $\left._{i, t}\right)$ are calculated from ParlGov (Döring and Manow 2012), supplemented with pres- 
idential election results from the United States. We use the GDP per capita measure from the Madison Project (Bolt and van Zanden 2013) as our measure for Growth ${ }_{i, t}^{\mathrm{M}}{ }^{29}$ Data for Growth $_{i, t}^{\mathrm{T} 5 \mathrm{M}}$ are taken from the World Top Incomes Database (WTID) provided by Alvarez et al. (2012), which provides measures of pre-tax total income drawn from national income tax records. We again measure election year growth rates as a weighted average of growth in the election year and in the prior year, as described for the election-study analyses.

In addition to providing top-income data for a relatively large number of countries, the WTID also allows us to probe the robustness of our findings to the use of different topincome measures. We present below results from models using income growth for the top $1 \%\left(\mathrm{Growth}_{i, t}^{\mathrm{T} 1 \mathrm{M}}\right)$ and provide results for income growth for the top $10 \%$ and top $0.1 \%$ in the appendix (see table E.3). We, further, take advantage of improved degrees of freedom to assess whether the prevailing level of inequality conditions the effect of top-income growth. To do so, we draw on the WTID's measures of the shares of total income accruing to the top $5 \%$ and the top $1 \%$ of the income distribution (Share ${ }_{i, t}^{\mathrm{T} 5}$ and Share ${ }_{i, t}^{\mathrm{T} 1}$ ).

As detailed in table 8 , the resulting combined data set provides us with up to 233 country election observations. ${ }^{30}$ Observations are drawn from the following 15 countries: Australia, Canada, Denmark, France, Germany, Italy, Japan, the Netherlands, New Zealand, Norway, Portugal, Spain, Sweden, the United Kingdom, and the United States. Further details on the sample can be found in the paper's appendix (section A.2).

As for the election survey analyses, we summarize our income data in figure 3, which displays a bivariate scatterplot of the mean growth rates and growth rates for the top $5 \%$ of earners. All data points are for election year observations that appear in our sample; the diagonal line represents equal growth rates. Once again, while we see a positive relationship between the two variables, we also see wide variation in the distribution of election year aggregate growth over which incumbent parties in our sample of country elections have presided. We also note that there is a greater spread in Growth ${ }^{\mathrm{T} 5 \mathrm{M}}$ than in Growth ${ }^{\mathrm{M}}$, implying greater variance in distributional outcomes, as be-

29. The Maddison data provide better coverage than the World Top Incomes Database (WTID), which we use for top-income growth, as the latter sometimes lacks data for mean income growth even in some places where it has top-income growth measures. Furthermore, the WTID lacks data at less than yearly intervals for some countries, making it more complicated, and assumption-laden, to construct annual growth rates.

30. The chief constraint on sample size is the availability of Growth ${ }^{\mathrm{TSM}}$ data.
Table 8. Summary Statistics for Variables Used in Time-Series Cross-Section Regressions

\begin{tabular}{lcrrrr}
\hline Variable & Mean & SD & Min & Max & $N$ \\
\hline VoteShare $_{i, e}^{\mathrm{PM}}$ & -2.0 & 5.94 & -28.3 & 17.2 & 235 \\
VoteShare $_{i, e}^{\mathrm{PM}}$ & 37.63 & 9.99 & 6.8 & 61.79 & 235 \\
Tenure $_{i, t}$ & 7.3 & 6.55 & .07 & 37.68 & 235 \\
Growth $_{i, t}^{\mathrm{M}}$ & .03 & .02 & -.05 & .12 & 235 \\
Growth $_{i, t}^{\mathrm{T} 5 \mathrm{M}}$ & .02 & .05 & -.15 & .24 & 225 \\
Share $_{i, t}^{\mathrm{T},}$ & 20.62 & 3.62 & 13.18 & 33.79 & 213 \\
Growth $_{i, t}^{\mathrm{T} 1 \mathrm{M}}$ & .03 & .07 & -.18 & .38 & 233 \\
Share $_{i, t}^{\mathrm{T}}$ & 8.04 & 2.33 & 3.98 & 17.96 & 222 \\
Tr & & & & &
\end{tabular}

tween the rich and the rest, than in aggregate outcomes - the focus of most of the economic voting literature to date. ${ }^{31}$

\section{Results}

The results of our aggregate, election-level analyses are presented in table 9. In this broader sample of countries, estimates of model 1 indicate that, controlling for growth at the top, we find little evidence that the electorate as a whole rewards incumbents for income growth for the bottom $95 \%$ (i.e., no effect of mean growth, controlling for top-5\% growth). By contrast, and in line with the election-study results, we see evidence of inequality demanding electoral behavior across the sample. The estimated coefficient on Growth ${ }^{\mathrm{T}}{ }^{\mathrm{M}}$ implies that a one standard deviation increase in top-5\% income growth, at the expense of the bottom 95\%, adds 0.82 percentage points to the incumbent's predicted vote share. Model 2 reveals how this CBEV effect is conditioned by the share of income going to the top $5 \%$. Here we see a strong negative interaction between Growth ${ }^{\mathrm{T} 5 \mathrm{M}}$ and Share ${ }^{\mathrm{T} 5}$, implying that the CBEV effect is at its largest when inequality is lowest and at its smallest when inequality is highest.

In the next two models, we examine the sensitivity of this finding to the choice of top-income measures, analyzing the effect of income growth among the richest $1 \%$. Model 3 yields no evidence of an unconditional effect of income growth among the top $1 \%$ (Growth ${ }^{\mathrm{T} 1 \mathrm{M}}$ ) on incumbent vote shares across the sample. In model 4 , however, we examine the effect conditional on very-top-income shares. When we interact Growth ${ }^{\mathrm{T} 1 \mathrm{M}}$ with the share of income going to the top $1 \%$, we see strong evidence of a positive response to rising inequality when inequality at the very top is relatively low. At relatively low levels of inequality, that is, the electoral fortunes of governing parties are enhanced by the concen-

\footnotetext{
31. The standard deviation of Growth ${ }^{\mathrm{TSM}}$ is 0.056 ; that of $\mathrm{Growth}^{\mathrm{M}}$ is
} 0.028 . 


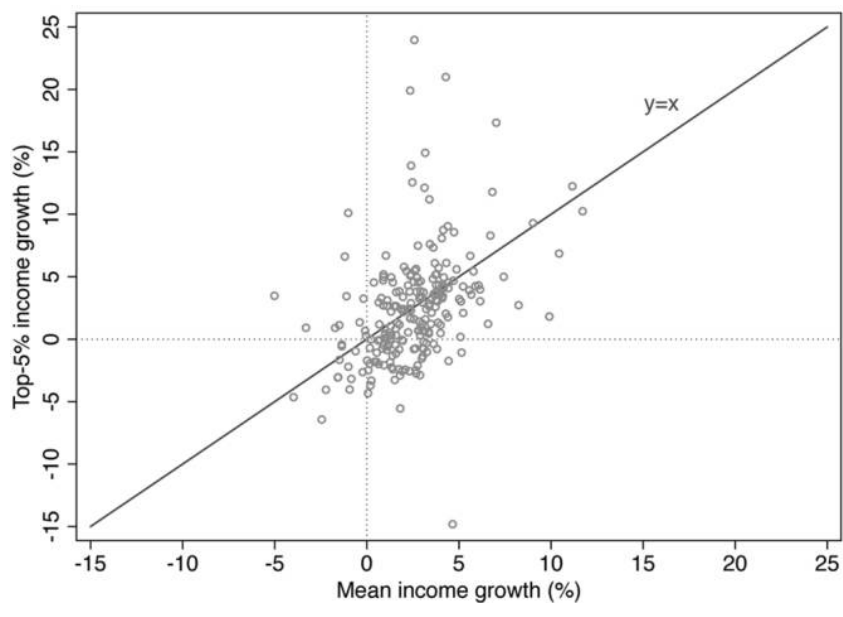

Figure 3. Scatter plot of mean income growth (Growth ${ }^{M}$ ) and top-income growth (Growth $^{\top 5 \mathrm{M}}$ ) for all election year observations in our main sample $(\rho=.41)$.

tration of aggregate economic gains on the richest $1 \%$ of earners.

At the same time, this conditioning effect of inequality suggests that - rather than generating a runaway, winner-take-all process - $\mathrm{CBEV}$ may be characterized by a self-limiting dynamic. To illustrate this effect, we use the estimates from model 2 to plot in figure $4 A$ the marginal effect (and 95\% confidence interval) of a one standard deviation change in Growth $^{\mathrm{T} 5 \mathrm{M}}$, conditional on Share ${ }^{\mathrm{T} 5}$. We do the equivalent for Growth $^{\mathrm{T} 1 \mathrm{M}}$ in figure $4 B$. As figure $4 A$ makes clear, we uncover a statistically significant demand for inequality when the share of national income captured by the top $5 \%$ is below about $21 \%$; this effect declines and moves toward inequality aversion at the top end of the sample range for top-income share (though effects at the top of the range are imprecisely estimated). The figure also illustrates the substantive significance of our findings. For example, at low levels of Share ${ }^{\mathrm{T} 5}$, we estimate that a standard deviation increase in Growth ${ }^{\mathrm{T} 5 \mathrm{M}}$ adds around 2 percentage points to the incumbent vote share, while the point estimate of the effect is estimated to be negative, albeit not statistically significant, at high levels of Share ${ }^{\mathrm{T} 5}$. Turning to figure $4 B$, for top $1 \%$ measures, the inferences are very similar. The key difference is that clear, statistically significant, inequality aversion emerges at high levels of Share ${ }^{\mathrm{T} 1}$. A one standard deviation increase in the growth rate for the top $1 \%$ is, at the top of the Share ${ }^{\mathrm{T} 1}$ sample range, associated with a vote loss of about 1.75 percentage points for the incumbent party.

We can also illustrate the conditioning effect of top-income shares in another way - by estimating CBEV coefficients separately for different periods of time and then showing how these effect sizes evolve with inequality. Figure 5 does this by plotting the estimated coefficient on Growth ${ }^{\mathrm{T5M}}$ (along with 90\% confidence intervals) for samples composed of observations in overlapping 20-year periods. On these estimated coefficients, we overlay the mean share of income not going to the top 5\% in each of these subsamples. (We reverse this measure to ease interpretation.) The figure demonstrates that cross-national CBEV effects have risen and fallen, over time, inversely with

Table 9. OLS Estimates of Coefficients for Predictors of Vote Share for the Party of the Prime Minister Incumbent (1945-2010)

\begin{tabular}{|c|c|c|c|c|c|c|c|c|c|c|c|c|}
\hline & \multicolumn{3}{|c|}{ (1) } & \multicolumn{3}{|c|}{ (2) } & \multicolumn{3}{|c|}{ (3) } & \multicolumn{3}{|c|}{ (4) } \\
\hline & $b$ & SE & $p$ & $b$ & SE & $p$ & $b$ & SE & $p$ & $b$ & SE & $p$ \\
\hline VoteShare $_{i, e-1}^{\mathrm{PM}}$ & -.15 & .04 & .00 & -.15 & .04 & .00 & -.14 & .03 & .00 & -.15 & .04 & .00 \\
\hline LogTenure $_{i, \mathrm{t}}$ & -1.08 & .44 & .03 & -1.02 & .48 & .05 & -1.08 & .43 & .02 & -1.03 & .47 & .04 \\
\hline Growth $_{i, t}^{\mathrm{M}}$ & 20.60 & 10.40 & .07 & 25.14 & 10.66 & .03 & 32.03 & 11.21 & .01 & 34.20 & 12.31 & .01 \\
\hline Growth $_{i, t}^{1,5 \mathrm{M}}$ & 16.31 & 9.53 & .11 & 87.98 & 29.92 & .01 & & & & & & \\
\hline Share $_{i, t}^{\mathrm{T} 5, t}$ & & & & -.01 & .06 & .83 & & & & & & \\
\hline Share $_{i, t}^{\text {T5 }} \times$ Growth $_{i, t}^{\mathrm{T} 5 \mathrm{M}}$ & & & & -3.34 & 1.46 & .04 & & & & & & \\
\hline Growth $_{i, t}^{\mathrm{T} 1 \mathrm{M}}$ & & & & & & & 3.39 & 4.49 & .46 & 34.10 & 11.65 & .01 \\
\hline Share $_{i, t}^{\mathrm{T} 1, \mathrm{l}}$ & & & & & & & & & & .12 & .08 & .19 \\
\hline Share $_{i, t}^{\text {T1 }} \times$ Growth $_{i, t}^{\mathrm{T} 1 \mathrm{M}}$ & & & & & & & & & & -3.17 & 1.02 & .01 \\
\hline Intercept & 4.85 & 1.41 & .00 & 4.78 & 1.86 & .02 & 4.55 & 1.32 & .00 & 3.73 & 1.35 & .01 \\
\hline$R^{2}$ & .15 & & & .15 & & & .13 & & & .14 & & \\
\hline $\mathrm{BIC}$ & 1,436 & & & 1,374 & & & 1,480 & & & 1,418 & & \\
\hline$N$ & 225 & & & 213 & & & 233 & & & 221 & & \\
\hline No. of countries & 15 & & & 15 & & & 16 & & & 16 & & \\
\hline
\end{tabular}

Note. Standard errors are clustered by country. 
A

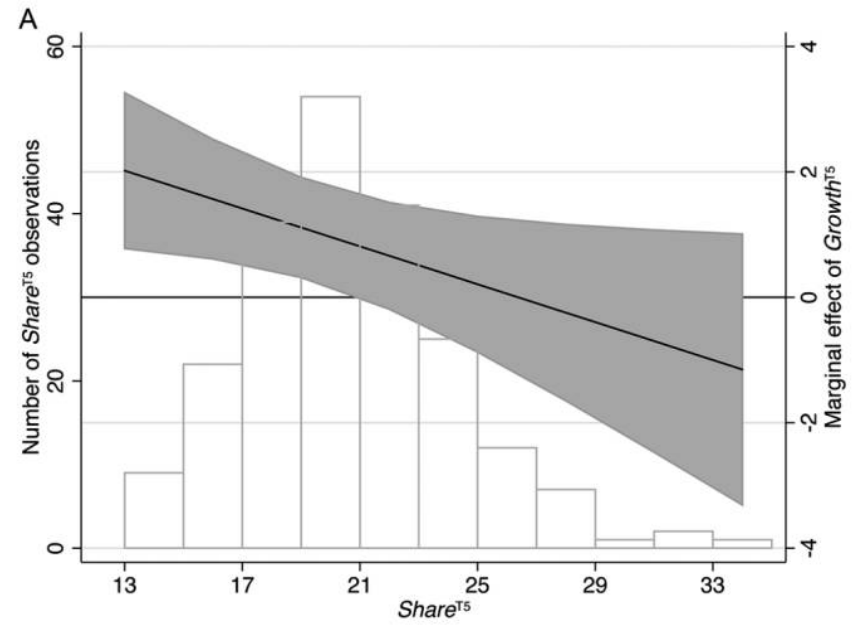

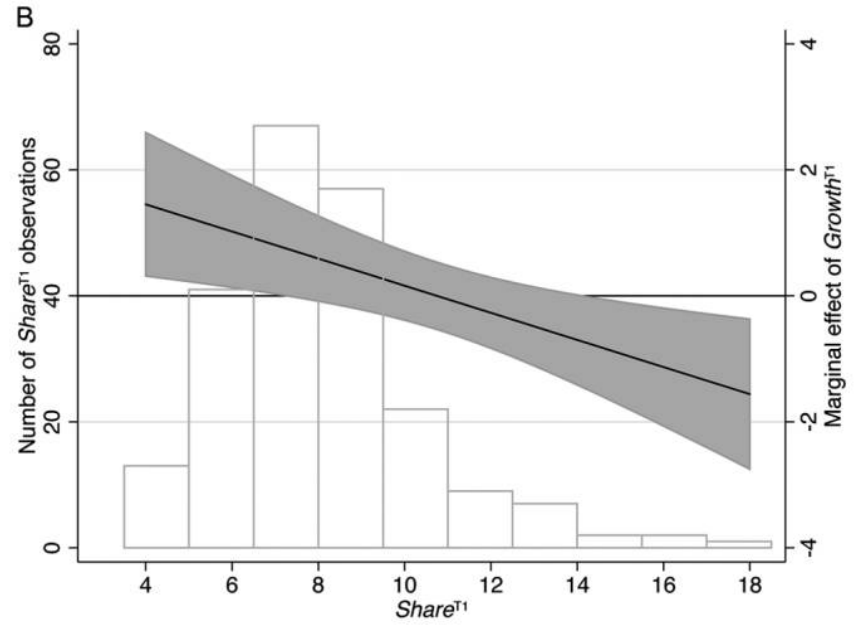

Figure 4. Estimated marginal effects, with $95 \%$ confidence intervals, of a standard deviation change in the indicated top-income growth measure, conditional on the relevant top-income share. A, Growth ${ }^{T_{5} M} ; B$, Growth ${ }^{T_{11} M}$. The figures are drawn for the sample range of Share ${ }^{T_{5}}$ and Share ${ }^{T_{1}}$, respectively. Vertical bars represent numbers of observations at each level of Share ${ }^{\mathrm{TX}}$. Estimates are based on models 2 and 4 of table 9.

inequality. The estimate for the 2005 sample suggests that the countries in our sample have now, on average, reached a level of inequality sufficient to make the maldistribution of income salient and to generate electoral incentives for incumbents to redistribute away from the very rich.

These cross-national inferences are remarkably robust. We document, in the appendix (section E), that the same pattern of results emerges from a very wide range of alternative specifications. The findings survive country-level jackknife standard errors, the use of a top $0.1 \%$ top-income threshold, controlling for unemployment rates in levels and in first differences, including inflation rates, including country-level fixed or random effects, including party-level random effects, and including a control for clarity of responsibility. ${ }^{32}$

\section{CONCLUSION}

Our analysis of voting patterns across a range of advanced industrialized democracies yields little evidence of patterns of electoral behavior that might deter governments from generating or permitting rising inequality. Low- and middleincome voters, both in our election-study data and our broader comparative analyses, seem remarkably poor at defendingand, indeed, seem to systematically undermine - their own distributive interests. We see widespread demand for inequality across the advanced democracies - an electoral bonus to

32. In the appendix, section C, we also examine moderation of Growth ${ }^{\text {Top5 }}$ effects in our individual-level, election-survey analyses by election-level Share ${ }^{\mathrm{T} 5}$ values. We find that higher Share ${ }^{\mathrm{T} 5}$ significantly dampens Growth ${ }^{\mathrm{Top} 5}$ 's effect for US voters (all and middle-income), Swedish voters (all, low-income, and middle-income), and Canadian voters (all and middle-income). The British results show moderation in the opposite direction. We see these election survey results as broadly consistent with the aggregate-level results. governments that preside over a concentration of gains at the top. And we find little evidence that governments pay a penalty among any income group or in the electorate as a whole for upwardly biased distributions of growth.

These results point to one important explanation for the increasing concentration of income in the hands of a small minority in political systems in which majorities (or, at least, pluralities) choose governments: on election day, those majorities are not looking out for their own economic selfinterest. The weakness of economic self-interest in shaping political attitudes and behavior is an old theme in the study of mass politics (Sears et al. 1980). Our results go much further, however, in demonstrating a systematic tendency among

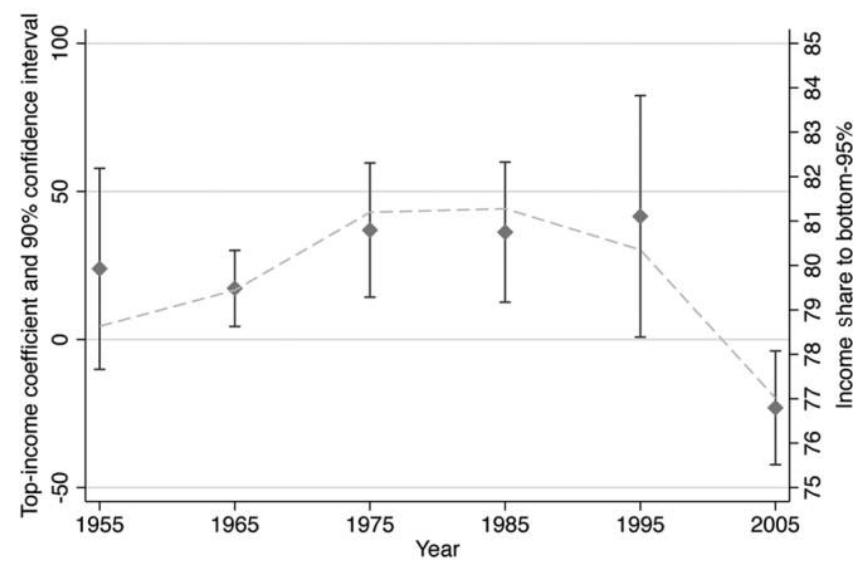

Figure 5. Top-income inferences through time. Estimates are based on regressions specified as in model 2 of table 9, but for 20-year periods centered on the year indicated (e.g., "1955" corresponds to a sample restriction of Year $\in[1945,1965])$. Note that samples overlap by 10-year periods. Point estimates of coefficients on Growth ${ }^{\text {T5 }}$ are shown together with 90\% confidence intervals (left axis). Share of income going to the bottom $95 \%$ of the income distribution, calculated as the mean value for the respective sample period, plotted in with a dashed gray line (right axis). 
lower- and middle-income voters to vote against their own economic interests. At the same time, our comparative results indicate that the electorate's tolerance for inequality has limits, diminishing as top-income shares rise. This pattern suggests that material distribution is commonly a dormant consideration in vote choice - but one that can be activated by a sufficient deterioration in objective distributional conditions. While governments can get pretty far in channeling welfare gains to the most affluent, they seem eventually to run up against the material demands of majorities.

An important avenue for further research is the identification of the mechanisms underlying class-biased economic voting. As suggested above, fundamental limits on voter cognition may incline citizens everywhere to take an oversimplified view of economic conditions - one that is blind to distributional features. Equally, however, our analysis supports explanations rooted in macro-level properties of political systems. While Bartels (2008) provides suggestive evidence of the operation of informational biases, other research designs could offer greater purchase on the precise mechanisms at work. An analysis of media content would permit tests for biases in the responsiveness of the news environment to the economic welfare of groups located at different points along the income distribution. An examination of rolling cross-section election-study data would permit a test for campaign effects on class biases in voting intentions, while campaign manifesto data could shed light on the conditions under which parties frame their campaign messages in distributive terms. And experimentation could illuminate how voters process information about the distributive profile of economic outcomes, as well as the informational and rhetorical conditions under which distributional (as opposed to aggregate) outcomes become salient. Future research might also look beyond informational mechanisms to explore possible ideational sources of CBEV, including common psychological tendencies for individuals to form attitudes and beliefs that justify existing social hierarchies, including those by which they are disadvantaged (Jost, Banaji, and Nosek 2004).

\section{ACKNOWLEDGMENTS}

We thank Mark Pickup, David Rueda, Michël Zemour, and audiences at the workshop on "Economic Inequality and the Quality of Democracy" at the University of British Columbia, the Centre for International Studies at Dublin City University, the Department of Political Science at Trinity College, Dublin, the European University Institute's seminars on Political Behavior and Political Economy, the Paris School of Economics' Political Economy of Institutional Change Seminar, and the American Political Science Association 2013 annual meeting for helpful comments on earlier drafts. Alecsandre
Dragne, Laura Levick, Katherine Tyson, Denver McNeney, and Pascal Doray-Demers provided invaluable research assistance. We are grateful to Richard Johnston for sharing Canadian election-study data.

\section{REFERENCES}

Achen, Christopher H., and Larry M. Bartels. 2004. "Musical Chairs: Pocketbook Voting and the Limits of Democratic Accountability." Presented at annual meeting of the American Political Science Association, September 1-5, Chicago.

Alvarez, Facundo, Anthony B. Atkinson, Thomas Piketty, and Emmanuel Saez. 2012. World Top Incomes Database. http://topincomes.g-mond .parisschoolofeconomics.eu/ (accessed February 21, 2013).

Anderson, Christopher J. 2000. "Economic Voting and Political Context: A Comparative Perspective." Electoral Studies 19 (2-3): 151-70.

Anderson, Christopher J. 2007. "The End of Economic Voting? Contingency Dilemmas and the Limits of Democratic Accountability." Annual Review of Political Science 10 (1): 271-96.

Ansolabehere, Stephen, Marc Meredith, and Erik Snowberg. 2014. "MecroEconomic Voting: Local Information and Micro-Perceptions of the Macro-Economy." Economics and Politics 26 (3): 380-410.

Bartels, Larry M. 2008. Unequal Democracy: The Political Economy of the New Gilded Age. Princeton, NJ: Princeton University Press.

Bolt, Jutta, and Jan Luiten van Zanden. 2013. "The First Update of the Maddison Project; Re-estimating Growth before 1820.” Working paper no. 4, Maddison Project.

Conover, Pamela Johnston, Stanley Feldman, and Kathleen Knight. 1986. "Judging Inflation and Unemployment: The Origins of Retrospective Evaluations." Lournal of Politics 48 (3): 565-88.

Cribb, Jonathan, Andrew Hood, Robert Joyce, and David Phillips. 2013. "Living Standards, Poverty and Inequality in the UK: 2013." IFS Report R81, Institute for Fiscal Studies, London.

Döring, Holger, and Philip Manow. 2012. Parliament and Government Composition Database (ParlGov): An Infrastructure for Empirical Information on Parties, Elections and Governments in Modern Democracies. Version 12/10, October.

Doyle, Gillian. 2002. Media Ownership: The Economics and Politics of Convergence and Concentration in the UK and European Media. Thousand Oaks, CA: Sage.

Duch, Raymond M., and Randolph T. Stevenson. 2008. The Economic Vote: How Political and Economic Institutions Condition Election Results. Cambridge: Cambridge University Press.

Evans, Geoffrey, and Robert Andersen. 2006. "The Political Conditioning of Economic Perceptions.” Iournal of Politics 68 (1): 194-207.

Evans, Geoffrey, and Mark Pickup. 2010. "Reversing the Causal Arrow: The Political Conditioning of Economic Perceptions in the 20002004 U.S. Presidential Election Cycle." Lournal of Politics 72 (4): 1236-51.

Evans, Geoffrey, and James Tilley. 2012. "How Parties Shape Class Politics: Explaining the Decline of the Class Basis of Party Support." British Journal of Political Science 42 (1): 137-61.

Fair, Ray C. 1978. "The Effect of Economic Events on Votes for President." Review of Economics and Statistics 60 (2): 159-173.

Fiorina, Morris P. 1981. Retrospective Voting in American National Elections. New Haven, CT: Yale University Press.

Gilens, Martin. 2012. Affluence and Influence: Economic Inequality and Political Power in America. Princeton, NJ: Princeton University Press.

Hacker, Jacob S. 2004. "Privatizing Risk without Privatizing the Welfare State: The Hidden Politics of Social Policy Retrenchment in the United States." American Political Science Review 98 (2): 243-60. 
Hacker, Jacob S., and Paul Pierson. 2011. Winner-Take-All Politics: How Washington Made the Rich Richer-and Turned Its Back on the Middle Class. New York: Simon \& Schuster.

Healy, Andrew, and Gabriel S. Lenz. 2014. "Substituting the End for the Whole: Why Voters Respond Primarily to the Election-Year Economy." American Journal of Political Science 58 (1): 31-47.

Hetherington, Marc J. 1996. "The Media's Role in Forming Voters' National Economic Evaluations in 1992." American Journal of Political Science 40 (2): 372-95.

Hibbs, Douglas A. 2000. "Bread and Peace Voting in U.S. Presidential Elections." Public Choice 104 (1): 149-80.

Hopkins, Daniel J. 2012. "Whose Economy? Perceptions of National Economic Performance during Unequal Growth." Public Opinion Ouarterly 76 (1): 50-71.

Huber, Gregory A., Seth J. Hill, and Gabriel S. Lenz. 2012. "Sources of Bias in Retrospective Decision Making: Experimental Evidence on Voters' Limitations in Controlling Incumbents." American Political Science Review 106 (4): 720-41.

Jost, John T., Mahzarin R. Banaji, and Brian A. Nosek. 2004. “A Decade of System Justification Theory: Accumulated Evidence of Conscious and Unconscious Bolstering of the Status Quo.” Political Psychology 25 (6): 881-919.

Kaplan, Steven N., and Joshua Rauh. 2013. "It's the Market: The Broad-Based Rise in the Return to Top Talent." Iournal of Economic Perspectives 27 (3): $35-55$.

Key, V. O. 1968. The Responsible Electorate: Rationality in Presidential Voting, 1936-1960. New York: Vintage.

Kiewiet, D. Roderick. 1983. Macroeconomics and Micropolitics: The Electoral Effects of Economic Issues. Chicago: University of Chicago Press.

Kinder, Donald R., and D. Roderick Kiewiet. 1981. "Sociotropic Politics: The American Case." British Journal of Political Science 11 (2): 12961.

Kramer, Gerald H. 1971. "Short-Term Fluctuations in U.S. Voting Behavior, 1896-1964.” American Political Science Review 65 (1): 131-43.

Lau, Richard R., and David P. Redlawsk. 2006. How Voters Decide: Information Processing in Election Campaigns. Cambridge: Cambridge University Press.

Lewis-Beck, Michael S. 1988. Economics and Elections: The Major Western Democracies. Ann Arbor: University of Michigan Press.

Lewis-Beck, Michael S., and Mary Stegmaier. 2013. "The VP-Function Revisited: A Survey of the Literature on Vote and Popularity Functions after over 40 Years." Public Choice 157 (3-4): 367-85.

Lin, Ken-Hou, and Donald Tomaskovic-Devey. 2013. "Financialization and U.S. Income Inequality, 1970-2008." American Journal of Sociology 118 (5): 1284-1329.

Meltzer, Allan H., and Scott F. Richard. 1981. "A Rational Theory of the Size of Government." Lournal of Political Economy 89 (5): 914-27.
Mutz, Diana C., and Jeffery J. Mondak. 1997. "Dimensions of Sociotropic Behavior: Group-Based Judgements of Fairness and Well-Being." American Journal of Political Science 41 (1): 284-308.

Nadeau, Richard, Richard G. Niemi, David P. Fan, and Timothy Amato. 1999. "Elite Economic Forecasts, Economic News, Mass Economic Judgments, and Presidential Approval." Journal of Politics 61 (1): 109-35.

Nannestad, Peter, and Martin Paldam. 1994. "The VP-Function: A Survey of the Literature on Vote and Popularity Functions after 25 Years." Public Choice 79 (3-4): 213-45.

OECD (Organization for Economic Cooperation and Development). 2008. Growing Unequal? Income Distribution and Poverty in OECD Countries. Paris: OECD.

Piketty, Thomas, and Emmanuel Saez. 2013. "Top Incomes and the Great Recession: Recent Evolutions and Policy Implications." IMF Economic Review 61 (3): 456-78.

Powell, G. Bingham, Jr., and Guy D. Whitten. 1993. “A Cross-National Analysis of Economic Voting: Taking Account of the Political Context." American Journal of Political Science 37 (2): 391-414.

Rosset, Jan, Nathalie Giger, and Julian Bernauer. 2013. "More Money, Fewer Problems? Cross-Level Effects of Economic Deprivation on Political Representation." West European Politics 36 (4): 817-35.

Saez, Emmanuel, and Michael R. Veall. 2005. "The Evolution of High Incomes in Northern America: Lessons from Canadian Evidence." American Economic Review 95 (3): 831-49.

Sanders, David, and Neil Gavin. 2004. "Television News, Economic Perceptions and Political Preferences in Britain, 1997-2001." Journal of Politics 66 (4): 1245-66

Schattschneider, Elmer Eric. 1960. The Semisovereign People: A Realist's View of Democracy in America. New York: Holt, Rinehart \& Winston.

Schudson, Michael. 2002. "The News Media as Political Institutions." Annual Review of Political Science 5 (1): 249-69.

Sears, David O., Richard R. Lau, Tom R. Tyler, and Harris M. Allen. 1980. "Self-Interest versus Symbolic Politics in Policy Attitudes and Presidential Voting." American Political Science Review 74 (3): 670-84.

Sniderman, Paul M., Richard A. Brody, and Philip E. Tetlock. 1991. Reasoning and Choice: Explorations in Political Psychology. Cambridge: Cambridge University Press.

Soroka, Stuart N. 2006. "Good News and Bad News: Asymmetric Responses to Economic Information.” Lournal of Politics 68 (2): 372-85.

Tavits, Margit, and Joshua D. Potter. 2014. "The Effect of Inequality and Social Identity on Party Strategies." American Journal of Political Science 59 (3): 744-58.

Tufte, Edward R. 1978. Political Control of the Economy. Princeton, NJ: Princeton University Press.

Wlezien, Christopher, Mark Franklin, and Daniel Twiggs. 1997. "Economic Perceptions and Vote Choice: Disentangling the Endogeneity." Political Behavior 19 (1): 7-17. 